\title{
STUDI PENGARUH PEMASANGAN ANGKUR DARI KOLOM KE DINDING BATA PADA RUMAH SEDERHANA AKIBAT BEBAN GEMPA
}

\author{
Febrin Anas Ismail ${ }^{1}$
}

\begin{abstract}
ABSTRAK
Gempa bumi yang melanda Sumatera Barat, 6 Maret 2007 merupakan salah satu bentuk pengulangan gempa di masa lalu dan merupakan petunjuk yang jelas bahwa belum banyak yang dilakukan berkaitan dengan rumah sederhana. Berdasarkan temuan di hampir semua gempa yang menimpa daerah Sumatera Barat, bangunan yang mengalami kerusakan dan roboh adalah rumah sederhana yang dibangun secara spontan (non engineered house), dimana bangunan dibangun berdasarkan pengalaman praktis tanpa perhitungan struktur. Salah satu bentuk kerusakan pada komponen non-struktur dan struktur adalah hubungan antara kolom dan dinding bata, dimana terjadi retak dan pemisahan antara kolom dan dinding akibat tidak ada angkur (stek).

Kebanyakan bangunan yang ada dibuat pada masa yang tidak mengingatkan orang akan bahaya gempa bumi. Untuk gempa yang tidak terlalu besar, bangunan kemungkinan akan tetap berdiri dengan sedikit kerusakan. Namun untuk mengantisipasi gempa bumi yang kuat dan mengurangi dampak buruk yang ditimbulkan, maka bangunan rumah berdinding tembok tersebut harus dibangun sesuai ketentuan konstruksi bangunan tahan gempa dengan memberikan perkuatan pada bagian-bagian tertentu seperti pemasangan angkur (stek) dari kolom ke dinding sebagai salah satu perkuatan hubungan.

Untuk mengetahui berapa besar pengaruh dari pasangan angkur (stek) dari kolom ke dinding bata, dilakukan penelitian terhadap dinding yang lengkap dengan sloof, kolom dan ringbalok. Pengujian dilakukan terhadap 2 benda uji yaitu benda uji yang menggunakan angkur (stek) dan tidak menggunakan angkur (stek), sehingga diharapkan dapat diketahui perilaku pemasangan angkur.
\end{abstract}

Kata Kunci : Gempa, angkur, rumah sederhana.

\section{PENDAHULUAN}

Gempa dahsyat yang melanda Sumatera Barat tanggal 6 Maret 2007 yang berkekuatan 5,8 skala Richter dengan dua kali gempa susulan yang magnitudonya lebih besar, yakni 6,1 SR dan 6,3 SR, telah meluluhlantakkan sejumlah kabupaten dan kota di Sumatera Barat. Episentrum tiga gempa itu relatif sama, di sekitar Malalo, pinggiran Danau Singkarak, atau $16 \mathrm{~km}$ barat daya Batusangkar, Kabupaten Tanah Datar. Akibat dari gempa ini tidak hanya menimbulkan koraban jiwa tapi juga merusak bangunan tempat tiggal masyarakat.

Kerusakan yang terjadi pada bangunan dibedakan atas kerusakan struktural berupa kerusakan pada balok, kolom, pelat lantai, dan pondasi sedangkan kerusakan non-struktural berupa kerusakan dinding, plafond, pintu dan jendela. Salah satu kerusakan non-struktural adalah kerusakan pada dinding bangunan, kerusakan ini pada umumnya terjadi karena tidak adanya angkur antara kolom dan dinding.

Oleh karena itu perlu dilakukan penelitian terhadap pengaruh pemasangan angkur dari kolom ke dinding bata sehingga didapatkan bagaimana sebenarnya pengaruh angkur pada bangunan. Tujuan

\footnotetext{
${ }^{1}$ Staf Pengajar Jurusan Teknik Sipil Fakultas Teknik Universitas Andalas, e-mail: febrin@ft.unand.ac.id
} 
dari penelitian ini adalah untuk mengetahui perilaku dinding bangunan yang menggunakan dan tidak menggunakan angkur (stek) sebagai salah satu perkuatan hubungan antara dinding dengan kolom yang bekerja sebagai satu kesatuan dalam menahan beban. Adapun manfaat dari penelitian ini adalah untuk referensi masyarakat dalam membangun rumah sederhana tahan gempa.

\section{DASAR}

\subsection{Gempa}

Gempa Bumi didefenisikan sebagai kejutan atau sentakan yang terjadi di dalam bumi yang getarannya dapat dirasakan di permukaaan bumi. Gempa disebabkan oleh peningkatan aktifitas geologi yang terjadi di dalam bumi, seperti terjadinya pergeseran-pergeseran antar lempeng benua pada daerah batas lempeng, meningkatnya suhu yang dapat menimbulkan penumpukan energi dalam waktu yang lama, sampai akhirnya terlepas dan menyebabkan getaran dalam tanah.

Di Indonesia terdapat beberapa pertemuan lempang atau kuat gempa seperti zona subduksi sumatera, patahan sumatera, dan lain-lain. Mengingat kondisi ini maka di Indonesia khususnya di daerah dekat pertemuan lempeng harus dibangun rumah yang aman terhadap gempa. Wilayah Indonesia adalah wilayah yang berada pada pertemuan 2 lempeng, yaitu lempeng Indo-Australia, Eurasia dan karena wilayah Indonesia merupakan wilayah yang rawan gempa maka di Indonesia harus diterapkan rumah yang tahan gempa.

\subsection{Analisa Statik Nonlinier (Pushover)}

Analisis statik nonlinier merupakan prosedur analisa untuk mengetahui keruntuhan suatu bangunan terhadap gempa, dikenal pula sebagai analisa pushover atau analisa beban dorong satik.

Pada proses pushover, struktur didorong sampai menagalami leleh disatu atau lebih lokasi di struktur tersebut. Kurva kapasitas akan memperlihatkan suatu kondisi linier sebelum mencapai kondisi leleh dan selanjutnya berperilaku non-linier. Kurva pushover dipengaruhi oleh pola distribusi gaya lateral yang digunakan sebagai beban dorong.

Tujuan analisa pushover adalah untuk memperkirakan gaya maksimum dan deformasi yaqng terjadi serta untuk memperoleh informasi bagian mana yang kritis. Selanjutnya dapat didefenisikan bagian-bagian yang memerlukan perhatian khusus untuk pendetailan atau stabilitasnya. Cukup banyak studi menunjukkan bahwa analisa statik pushover dapat memberikan hasil mencukupi (dibandingkan dengan hasil analisa dinamik nonlinier) untuk bangunan regular dan tidak tinggi.

Analisa pushover dapat digunakan sebagai alat bantu untuk perencanaan tahan gempa, asalkan menyesuaikan dengan keterbatasan yang ada, yaitu:

- Hasil analisa pushover masih merupakan pendekatan, karena bagaimanapun perilaku gempa yang sebenarnya adalah bersifat bolak-balik melalui suatu siklus tertentu, sedangkan sifat pembebanan pada analisa pushover adalah statik monotonik.

- Pemelihan pola beban lateral yang digunakan dalam analisa adalah sangat penting.

- Untuk membuat model analisa nonlinier akan lebih rumit dibanding model analisis linier. Model tersebut harus memperhitungkan karakteristik inelastik beban-deformasi dari elemenelemen yang penting.

\subsection{Rumah Sederhana (Non-Engineered House)}

Pengertian rumah sederhana (non engineered house) adalah bangunan rumah tinggal dan bangunan komersil sampai 2 lantai yang dibangun oleh pemilik, menggunakan tukang, bahan bangunan yang didapat setempat, tanpa bantuan arsitek maupun ahli struktur (Teddy Boen). 
Pengerjaan bangunan yang hanya melibatkan pekerja atau tukang setempat yang tidak kompeten membuat kualitas pekerjaan yang dihasilkan rendah. Pengerjaan hanya didasarkan pada perkiraan atau pengalaman membangun sebelumnya.

\subsection{Dinding tembok dengan Perkuatan Struktur Rangka}

Dinding tembokan dibuat dari berbagai macam material yang memiliki karakteristik yang berbedabeda, meskipun demikian bahan-bahan tersebut diharapkan dapat bekerja sebagai satu kesatuan dalam beban yang bekerja baik dalam arah vertikal (searah gravitasi) maupun ke arah horisontal (beban lateral: angin dan gempa). Kekuatan dinding tembok dipengaruhi oleh :
1. Kekuatan bata
2. Kekuatan adukan siar
3. Ketebalan adukan siar
4. Tingkat awal penyerapan air oleh bata
5. Variasi ukuran bata
6. Mutu pengerjaan
7. Perawatan

Kolom dan balok berfungsi sebagai perkuatan dinding tembokan, untuk bangunan rumah tinggal dan bangunan sederhana satu lantai biasanya struktur rangka tersebut tidak dihitung secara detail tetapi hanya didasarkan pada ukuran dimensi tertentu yang sudah baku sehingga seringkali disebut sebagai kolom dan balok praktis.

\subsection{Bentuk dan Cara Pemasangan Angkur (stek)}

Untuk memastikan bahwa struktur bangunan bekerja sebagai satu kesatuan yang utuh, setiap bagian dinding tembok harus dibingkai dengan kolom dan balok dengan luasan maksimum $9 \mathrm{~m}^{2}$, atau kolom harus dipasang setiap jarak maksimum $3 \mathrm{~m}$ dengan dilengkapi balok sloof dan ringbalok. Besi tulangan dipasang sebagai angkur (stek) dan ditanam di dalam adukan siar horisontal di setiap 6 lapis bata (sekitar $35 \mathrm{~cm}$ ) dengan kedalaman (panjang penjangkaran) minimal $30 \mathrm{~cm}$ di setiap bagian untuk memperkuat hubungan antara dinding dengan kolom dan balok sehingga dapat bekerja sebagai satu kesatuan dalam menahan beban. Angkur (stek) juga berfungsi membantu struktur utama agar terjadi aksi komposit dan supaya batu bata tidak terjatuh kebawah jika gempa ada. Kejadian tanpa angkur (stek) banyak terjadi sewaktu gempa yang mana kolom tetap berdiri namun dinding bata jatuh karena tidak mempunyai angkur.

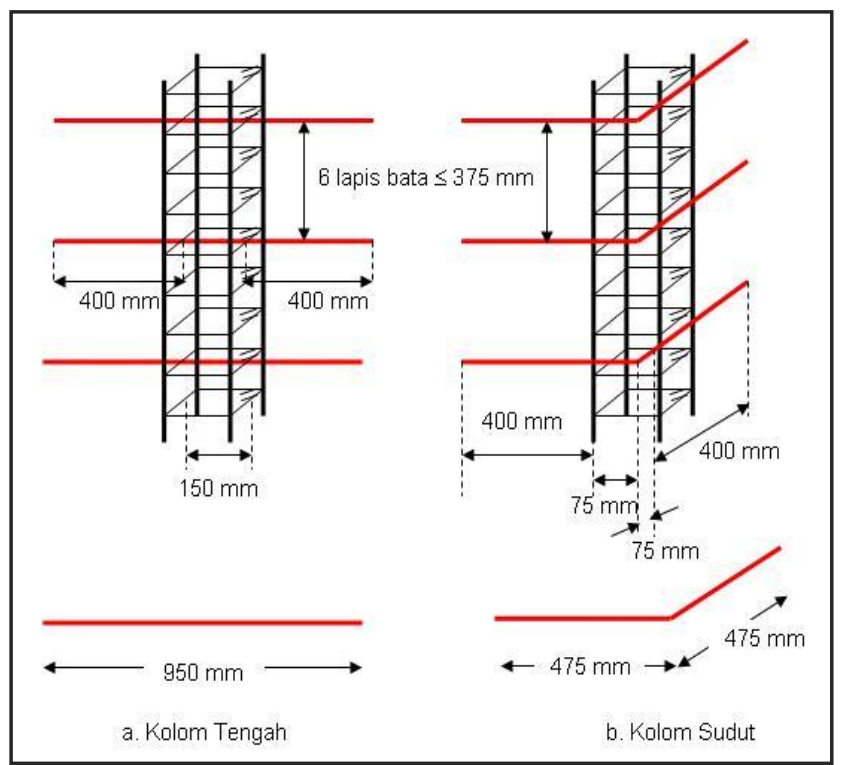




\section{PROSEDUR DAN HASIL KERJA}

\subsection{Persiapan Bahan dan Material Percobaan}

Benda uji yang akan dibuat merupakan sebuah dinding yang lengkap dengan kolom, ringbalok, dan sloof yang berukuran $1,5 \mathrm{~m} \times 1,5 \mathrm{~m}$. Adapun bahan-bahan yang diperlukan dalam penbuatan benda uji ini antara lain :
a. Semen
b. Pasir (agregat halus)
c. Kerikil (agregat kasar)
d. Besi/Baja Tulangan
e. Batu bata
f. Air
g. Kayu

\subsection{Pembuatan Benda Uji}

Benda yang akan dilakukan pengujian nantinya adalah berupa dinding yang lengkap dengan sloof, kolom, ringbaloknya. Pengujian ini akan dilakukan terhadap 2 benda uji yaitu :

A. Benda Uji yang Menggunakan Angkur (stek) dari Kolom ke Dinding.

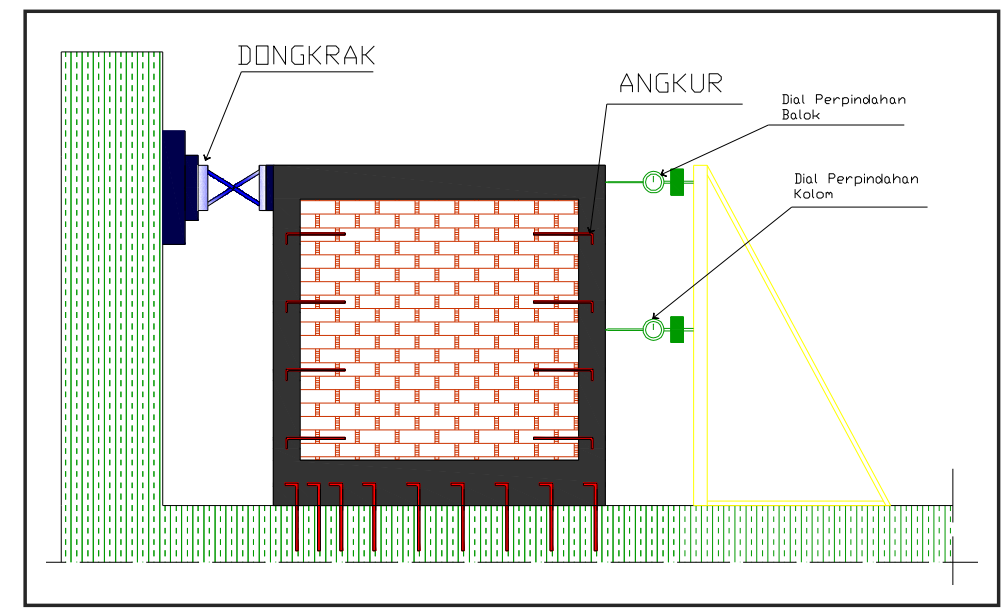

Gambar 2. Menggunakan Angkur (Stek) dari Kolom ke Dinding

B. Benda Uji yang Tidak Menggunakan Angkur (stek) dari Kolom ke Dinding

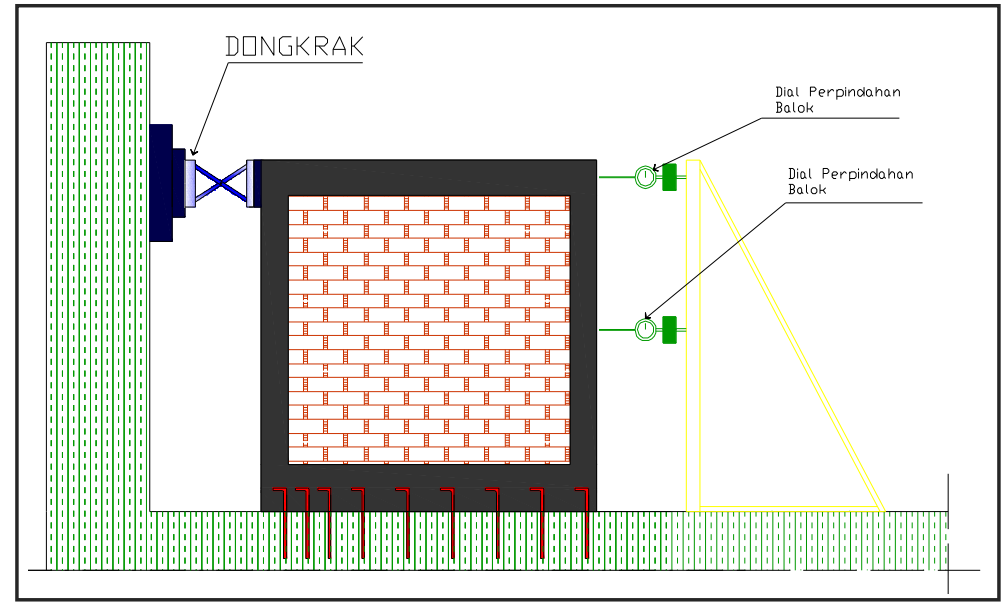

Gambar 3. Tidak Menggunakan Angkur (Stek) dari Kolom ke Dinding 
Benda uji yang akan dibuat berukuran $1,5 \mathrm{~m} \times 1,5 \mathrm{~m}$. Adapun prosedur kerja dalam pembuatan benda uji ini adalah sebagai berikut :

a. Benda uji yang dibuat langsung ditempatkan pada lantai yang sebelumnya telah dibor sebagai tempat pengangkuran dari sloof ke lantai agar benda uji tidak bergerak dan berjarak $\pm 50 \mathrm{~cm}$ ke kolom, seperti yang terlihat pada gambar :

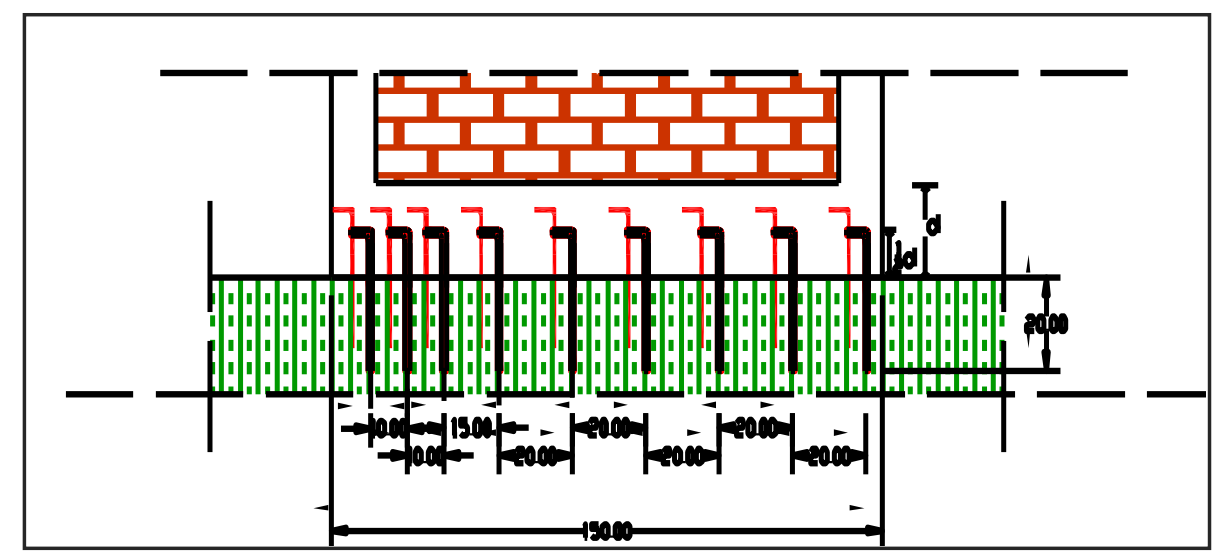

Gambar 4. Detail Jarak Pasangan Angkur

Diameter angkur (stek) yang dipakai dari sloof ke pelat lantai adalah Ø $12 \mathrm{~mm}$.

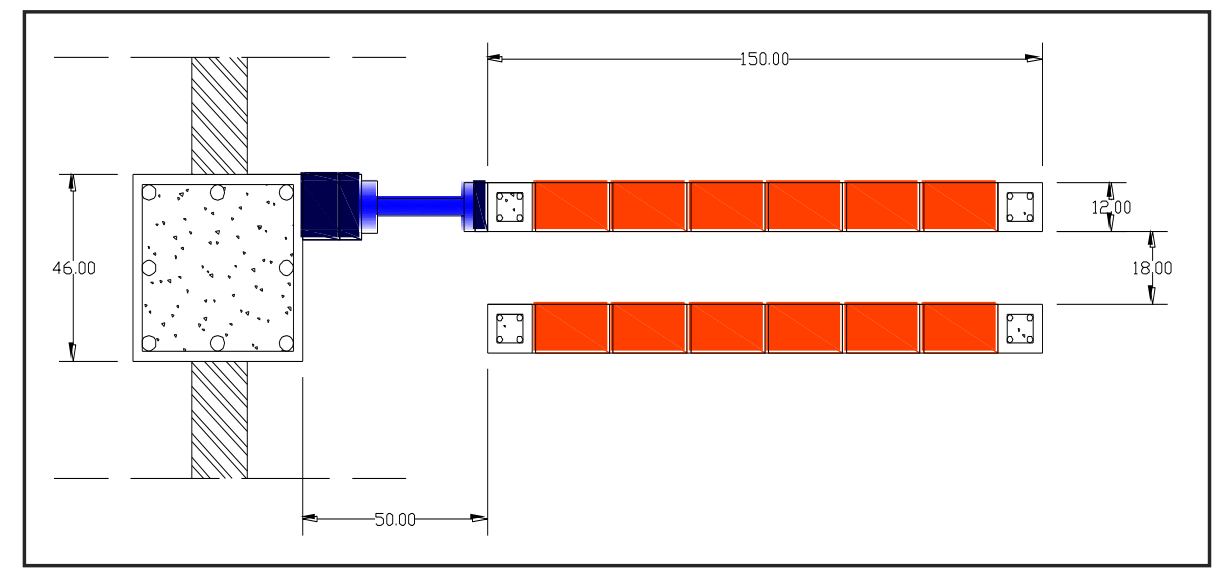

Gambar 5. Detail Pemasangan Benda Uji

b. Pekerjaan selanjutnya adalah merakit tulangan sloof, kolom, balok dan angkur (stek) yang akan digunakan. Ukuran-ukuran beton bertulang yang digunakan adalah:
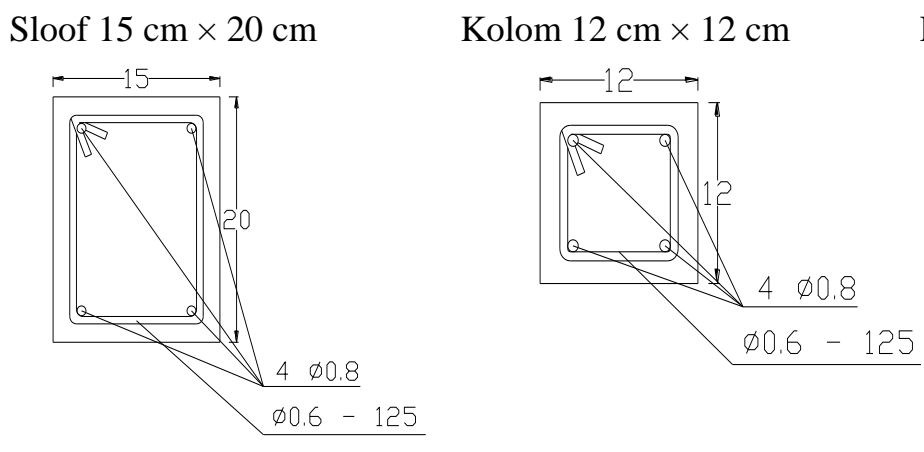

Ring Balok $11 \mathrm{~cm} \times 15 \mathrm{~cm}$

Dalam pembuatan sengkang, sengkang harus memiliki seismic hook (bengkokan) sepanjang $6 \mathrm{D}$, seperti yang terlihat pada gambar berikut. 

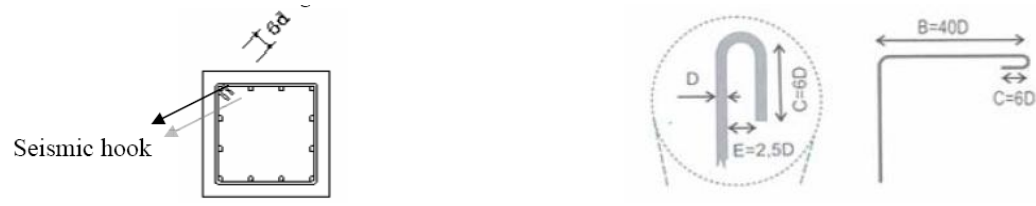

c. Pekerjaan selanjutnya adalah pekerjaan sloof, yang meliputi :

- Pembuatan bekisting sloof.

- Merangkai tulangan sloof dengan tulangan kolom (dibuat dengan menggunakan angkur/ stek dan tidak menggunakan angkur).

d. Pengecoran sloof, untuk adukan betonya menggunakan perbandingan 1 semen $: 2$ pasir : 3 kerikil

e. Setelah sloof mengering, pekerjaan selanjutnya adalah pekerjaan dinding bata, dengan mortar (spesi) digunakan setebal $1 \mathrm{~cm}$ dan perbandingannya 1 semen : 4 pasir.

f. Setelah pekerjaan dinding bata selesai dan sudah mengering, pekerjaan selanjutnya adalah pekerjaan kolom dan ringbalok yang meliputi:

- Merangkai tulangan kolom dengan tulangan ring balok, untuk sambungan sudut antara kolom dan ringbalok dapat dilihat pada gambar berikut.

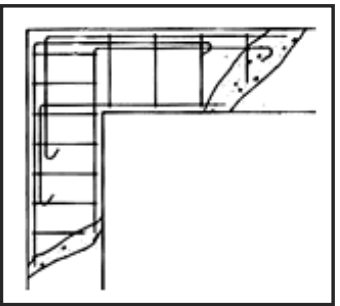

- Pembuatan bekisting kolom dan ringbalok.

- Pengecoran kolom dan ringbalok yang dilakukan serentak atau bersamaan, untuk adukan betonya juga menggunakan perbandingan 1 semen : 2 Pasir : 3 kerikil.

\section{g. Benda Uji}

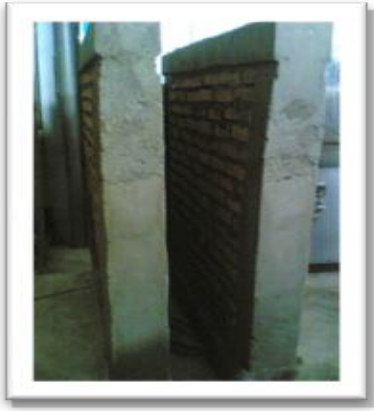

Gambar 6. Benda Uji

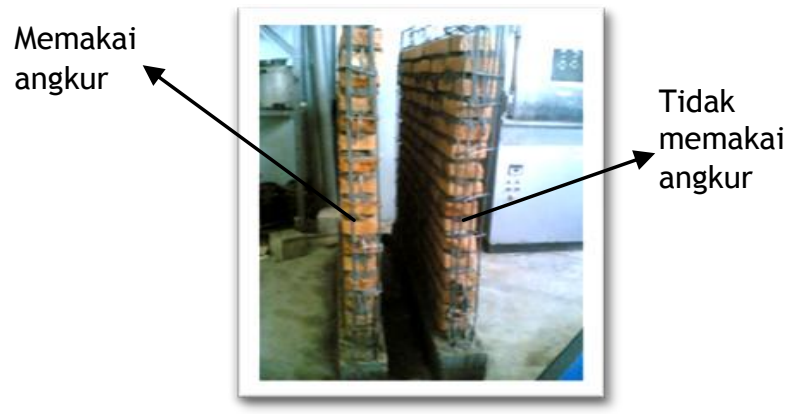

Gambar 7. Perbedaan Benda Uji

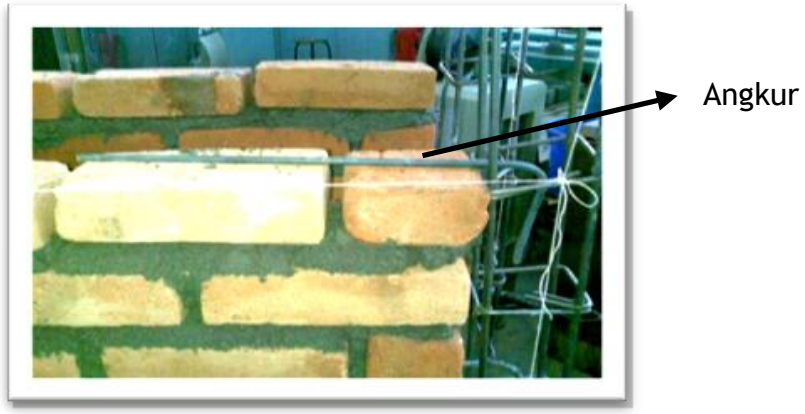

Gambar 8. Detail Pemasangan Angkur 


\section{ANALISA DAN PEMBAHASAN}

Tabel 1. Data Hasil Percobaan pada Benda Uji yang Menggunakan Angkur (Stek)

\begin{tabular}{|c|c|c|c|}
\hline \multirow{2}{*}{ No. } & \multirow{2}{*}{ Beban $(\mathbf{P})$} & \multicolumn{2}{|c|}{ Perpindahan $(\delta)$} \\
\cline { 3 - 4 } & & Balok & kolom \\
\hline 1. & 0 & 0.0 & 0.0 \\
\hline 2. & 200 & 0.0 & 0.0 \\
\hline 3. & 400 & 0.0 & 0.0 \\
\hline 4. & 600 & 0.2 & 0.1 \\
\hline 5. & 800 & 0.4 & 0.2 \\
\hline 6. & 1000 & 0.7 & 0.3 \\
\hline 7. & 1200 & 1.0 & 0.4 \\
\hline 8. & 1400 & 1.4 & 0.5 \\
\hline 9. & 1600 & 2.4 & 1.2 \\
\hline $\mathbf{1 0 .}$ & $\mathbf{1 8 0 0}$ & $\mathbf{3 . 9}$ & $\mathbf{1 . 6}$ \\
\hline 11. & 1500 & 4.6 & 2.1 \\
\hline 12. & 1600 & 5.4 & 2.5 \\
\hline 13. & 1700 & 6.4 & 3.0 \\
\hline
\end{tabular}

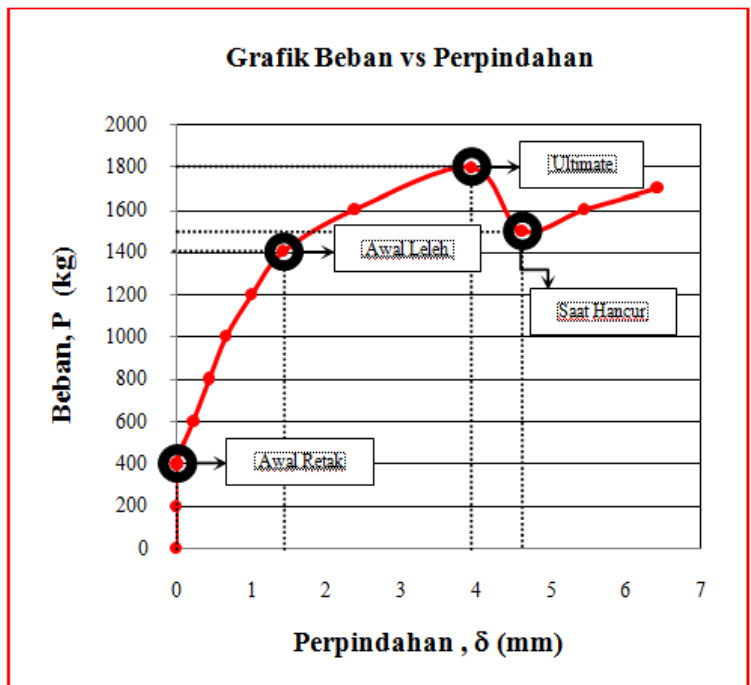

Gambar 9. Grafik Beban vs Perpindahan yang Terjadi pada Balok

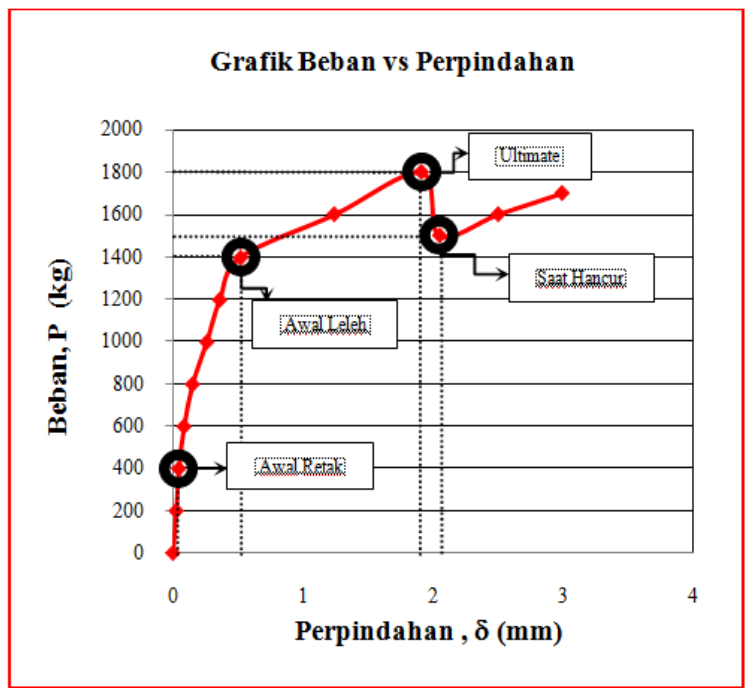

Gambar 10. Grafik Beban vs Perpindahan yang Terjadi pada Kolom

1. Awal Retak

a. Retak pertama (first crack) pada benda uji yang menggunakan angkur (stek) terjadi pada ujung balok.

b. Retak pertama (first crack) yang ditandai dengan tidak liniernya kurva beban dengan perpindahan akibat beban pushover sebesar $400 \mathrm{~kg}$.

c. Perpindahan yang terjadi pada retak pertama ini adalah sebesar $0,2 \mathrm{~mm}$ pada balok dan $0,1 \mathrm{~mm}$ pada kolom.

2. Awal Leleh

a. Awal leleh terjadi setelah beton pada kolom mengalami retak dan tulangan yang mulai leleh. 
b. Pada awal leleh terjadi pada beban pushover sebesar $1400 \mathrm{~kg}$.

c. Perpindahan yang terjadi pada awal leleh ini adalah sebesar $1,4 \mathrm{~mm}$ pada balok dan 0,5 mm pada kolom.

3. Ultimate

a. Ultimate terjadi ketika beban yang mampu dipikul oleh portal adalah beban maksimum.

b. Pada saat ultimate terjadi akibat beban pushover sebesar $1800 \mathrm{~kg}$

c. Perpindahan yang terjadi pada saat ultimate adalah sebesar $6,1 \mathrm{~mm}$ pada balok dan 2,6 mm pada kolom.

4. Hancur

a. Ini terjadi ketika beban tidak lagi bertambah dan beton mulai hancur.

b. Pada saat hancur terjadi akibat beban $1500 \mathrm{~kg}$

c. Perpindahan yang terjadi pada saat hancur adalah $4,6 \mathrm{~mm}$ pada balok dan $2,1 \mathrm{~mm}$ pada kolom.

\section{KESIMPULAN}

Berdasarkan penelitian yang telah dilakukan, dapat diambil kesimpulan bahwa:

1. Benda uji yang menggunakan angkur (stek) menghasilkan pola retak diagonal tetapi tidak mengakibaktkan terpisahnya dinding bata dengan kolom.

2. Benda uji yang tidak menggunakan angkur (stek) menghasilkan pola retak diagonal tetapi juga mengakibatkan terpisahya antara dinding bata dengan kolom.

3. Pemasangan angkur (stek) dari kolom ke dinding dapat meningkatkan perkuatan hubungan antara dinding bata dengan kolom.

4. Pemasangan angkur (stek) dari dinding bata ke kolom juga berfungsi untuk mendukung aksi komposit satu sama lain dalam hal menahan beban gempa.

5. Hubungan antara kolom pengaku dinding dengan dinding tembok menggunakan angkur $\varnothing 8$ $\mathrm{mm}$ panjang $30 \mathrm{~cm}$ setiap 6 lapis bata atau 3 lapis batako.

6. Prinsip utama bangunan tahan gempa adalah adanya kesatuan dari struktur bangunan, semua unsur bekerja bersama-sama sebagai satu kesatuan, jadi tidak bekerja secara terpisah.

\section{DAFTAR KEPUSTAKAAN}

Boen, T. 1983, Manual Bangunan Tahan Gempa (Rumah Tinggal), Yayasan Lembaga Penyelidikan Masalah Bangunan.

Boen, T. 2000a, Bangunan Rumah Tinggal Sederhana: Belajar dari Kerusakan Akibat Gempa, Prosiding Lokakarya Nasional Bangunan Sederhana Tahan Gempa, UII, Yogyakarta.

Boen T. 2000b, Gempa Bumi Bengkulu: Fenomena dan Perbaikan / Perkuatan Bangunan (Bedasarkan Hasil Pengamatan Bangunan yang Rusak akibat Gempa Bumi Bengkulu 4 Juni 2000, Teddy Boen dan Rekan, Jakarta.

SNI 03-1726-2002, Tata Cara Perencanaan Ketahanan Gempa Untuk Bangunan.

SNI 03 - 6816 - 2002, Tata Cara Pendetailan Penulangan Beton Bertulang Indonesia.

SKBI (1987). "Petunjuk Perencanaan Beton Bertulang Dan Struktur Dinding Bertulang untuk Rumah dan gedung". Departemen Pekerjaan Umum, Jakarta. 